\title{
Cost Benefit Analysis of Use of Community Based Distributors in Promoting Access to Family Planning Services in Rural Communities in North Western Nigeria
}

\author{
Onoriode Ezire ${ }^{1^{*}}$, Isa Saidu Babale ${ }^{2}$, Dr Badamasi Usman ${ }^{3}$, Aliyu Guraguri ${ }^{4}$ and Omokhudu Idogho ${ }^{5}$
}

${ }^{1}$ Research and Evaluation Division, Society for Family Health, Abuja, Nigeria

${ }^{2}$ Association for Reproductive and Family Health, Abuja, Nigeria

${ }^{3}$ Bayero University, Kano

${ }^{4}$ Association for Reproductive and Family Health, Abuja, Nigeria

${ }^{5}$ Enhancing HIV and AIDS response in Nigeria, Abuja, Nigeria

\begin{abstract}
Background: Contraceptive use in Nigeria is still very low (15.5\%) while total fertility rate is still very high (5.5). Access and uptake of family planning services in rural communities is lower than the national average. In Nigeria, over $60 \%$ of the population resides in rural localities. One of the factors limiting access to family planning services is the very limited number of trained health care providers as ratio of one medical personnel to the population is 1:100,000. Amidst the current resource constraint in the country is the use of community-based distributors (CBD) an effective option in promoting family planning services?
\end{abstract}

Methods: Cost and health benefit data were collected from a project implemented in Nigeria. We defined cost from the provider's perspective. We estimated health benefit using couple year of protection (CYP) and Disability Adjusted Life Year (DALY). Effectiveness determined using the WHO cost effectiveness threshold.

Results: Over 25 million CYP was gained and 39,714 DALY averted. Total cost was around $\$ 1.19 \mathrm{~m}$ with an average cost per person reached, $\$ 0.78$. We estimated the incremental effectiveness ratio to be $\$ 29.94$, which is lesser than Nigeria GDP per capital $(\$ 3,000)$.

Conclusion: While working on the long-term goal of increasing the number of trained medical staff, the use of CBDs is an effective strategy instead of a do nothing situation. We recommend the use of CBDs in scaling up not just FP but other preventive healthcare needs of rural communities, as it is sustaining, community owned and costeffective.

Keywords: Family planning; Cost effectiveness; Cost effectiveness ratio; Nigeria; DALY; Couple year of protection

\section{Abbreviations}

ASFT: Age Specific Fertility Rate; BCC: Behaviour Change Communication; CBD: Community Based Distributors; CBOs: Community Based Organizations; CEA: Cost Effectiveness Analysis; CHOICE: CHOosing Interventions that is Cost-Effective; CYP: Couple Year of Protection; DALY: Disability Life Adjusted Year; FP: Family Planning; GDP: Gross Domestic Product; HIV: Human Immunodeficiency Virus; ICER: Incremental Cost Effectiveness Ratio; M\&E: Monitoring and Evaluation; MIS: Management Information System; OC: Oral Contraceptive; PSI: Population Services International; SPO: State Programme Officers; TFR: Total Fertility Rate; UK: United Kingdom; UNFPA: United Nation Fund for Population Activities; WHO: World Health Organization; YLD: Years lost due to Disability; YLL: Year of Life Lost

\section{Background}

Nigeria is ranked 13th among countries with the highest fertility rate in the World-5.5 births per woman [1]. In Nigeria, Rural areas have a much higher Total Fertility Rates (TFR) than urban areas (6.2 versus 4.7), and there are large urban rural differences in Age Specific Fertility Rate (ASFRs) for all age groups. The largest variations are in the 1519 and 20-24 age groups; in these groups, the rates for rural women exceed those for urban women (100 and 79 births per 1,000 women respectively). Adolescent fertility rate in rural areas more than doubles that in urban areas [2]. North Western Nigeria has health indexes worst than the national average [2]. There are different approaches to scaling up access to family planning services of which the use of community-based distributors is one of the approaches. Community-based distribution (CBD) is a strategy that relies on trained non-professional members of the community to provide health services directly to other members of the community. In the case of family planning, these services include provision of information and services on temporary contraceptive methods, usually the pill, condoms and other barrier methods. Other primary health care services may also be provided through CBD, including oral rehydration therapy and treatment for malaria $[3,4]$. CBD programs provide commodities through a network of distributors who provide services directly to the public. These distributors can be salaried health professionals or unsalaried community residents with little or no medical training. CBD's niche is that it makes contraceptives

${ }^{*}$ Corresponding author: Onoriode Ezire, No 8, Port Harcourt Crescent, Off Gimbiya Street, Area 11, Garki, FCT, Abuja, Nigeria, Tel: +2348060087524; E-mail: oeziree@yahoo.com

Received July 16, 2015, 2015; Accepted August 12, 2015; Published August 19, 2015

Citation: Ezire O, Babale IS, Usman DB, Guraguri A, Idogho O (2015) Cost Benefit Analysis of Use of Community Based Distributors in Promoting Access to Family Planning Services in Rural Communities in North Western Nigeria. J Trop Dis 3: 172. doi:10.4172/2329891X.1000172

Copyright: () 2015 Ezire O, et al. This is an open-access article distributed under the terms of the Creative Commons Attribution License, which permits unrestricted use, distribution, and reproduction in any medium, provided the original author and source are credited. 
available to clients at health posts or other small retail outlets usually located in areas distant from commercial providers of pharmaceuticals. Some CBD programs also provide methods to women in their homes. CBD program activities include educating and motivating clients to use oral contraceptives (OCs), transporting oral contraceptives to distributors and then to the client [5]. Community based distributors can multi task in terms of service provision. Evidences suggest that integrating Human Inmmunodeficiency virus (HIV) information and other health services into community-based distribution programs does not distract from the family planning and reproductive health aspects of program and can be a cost-effective way to reach a large population with services [6].

The use of cost-effectiveness analysis (CEA) within decisionmaking processes in health is increasingly common globally [7]. CEA offers policy makers a rational basis for deciding to reallocate resources between interventions to achieve social objectives [7].

\section{Rationale for the Study}

While there is a lot of literature on the benefits and use of community based distributors of health commodities, there is very limited evidence especially in Sub Saharan Africa of their cost effectiveness especially at the health impact level [8]. Few that exist uses measurements that makes it difficult to compare across intervention areas. This study is an attempt to bridge this gap by providing scientific evidence on cost effectiveness of the use of community based distributors especially in rural communities in Nigeria in promoting access to family planning services.

\section{Research questions}

a) How cost effective is a large CBD program

b) What are the health benefits of a large CBD program?

c) Using WHO effective threshold, is the use of CBD agent a cost effective approach in promoting FP services?

\section{Hypothesis}

Null Hypothesis: The use of CBD is not a cost effective way in promoting access to family planning services in Nigeria.

\section{Methodology}

The study is based on secondary analysis of existing data (financial and health outcome) from a project being implemented in Nigeria. The financial and health outcome data collected covers the period: 2013 to 2014 and from four Nigerian states (Katsina, Jigawa, Kebbi and Zamfara states)

\section{Estimating and categorization of cost}

Estimate of cost of contraceptives in this study is based on the UNFPA guide for costing FP services [5]. In this study we included costs of contraceptives, labour and vehicles to move the contraceptives, labour to promote use and educate clients and to supervise distributors, and supplies (flip charts, folios) to educate clients and distributors.

We defined cost from the project perspective and not from the societal perspective. This was because of the challenge of getting actual cost from societal perspective. The estimates and categories of cost used are explained below:

Program related cost: This captures all direct and indirect costs of engaging Community Based Organizations (CBOs), that were directly responsible for the supervision of the CBDs. This cost covers monthly allowances given to staff of the $\mathrm{CBO}$ contracted by the project, overhead cost of the $\mathrm{CBO}$ etc. (two CBOs were contracted in each state bringing the total to eight). $100 \%$ of the cost of contracting the CBOs retired and accepted was used for the analysis.

Purchase of commodities: Purchase of commodities covers the cost of purchase of the following commodities: oral contraceptive pill (Commbination3), Water purifiers (Water guard, and PUR), Cycle Beads, male and female condoms. This cost covers both the cost of actual purchases, warehousing and logistics to take them to delivery point (the CBDs)

Staff capacity building: Selected Community Based Distributors were trained on effective behaviour change communication (BCC) and also on basic concept of family planning. They were also introduced to the commodities they are expected to distribute. This cost covers all cost related to the trainings. The cost expended as recorded in the training expense reports was used.

Meetings with community leaders: Activities were carried out to sensitize the community leaders on the benefit of Family Planning (FP) and to gain their support. Cost expended included transportation and other logistics to facilitate such meetings. Time spent by the programme team was not included as it was captured under salary.

Review meetings with CBO: As part of efforts to ensure planned activities were implemented as planned, the Community based organizations supervising the CBDs held monthly review meetings with the CBDs. These meeting serve as avenue to provide update on what has been done, possible challenges faced in the implementation of the intervention, etc. Cost elements include refreshment during the meetings and token (transportation) given to the CBD for participation.

Monitoring of CBD by $\mathrm{CBO}$ and M\&E Officer: To ensure the quality of services provided by the CBDs meets minimum standards, periodic monitoring visits were paid to observe Interpersonal communication session, review of MIS forms, check stock and CBD record keeping etc. Cost expended ware largely travel related and include transportation, per Diem and hotel accommodation.

Production of CBD kits: Bags, Apron, Hijab were given to the CBDs for easy identification and for carrying materials during fieldwork. This cost covers both the production and distribution of the kits to the CBDs. $100 \%$ of what was retired for this was used for the analysis.

Production of registers: Management Information System (MIS) materials were produced for $\mathrm{CBD}$, the $\mathrm{CBO}$ and the Programme M\&E Officer. The MIS forms produced include: Daily registers, monthly summary registers and Referral forms. These cost elements cover the production, piloting, printing and distribution of these forms.

Production of referral boxes: Referral boxes were produced and placed at referral centres. This cost covered the cost of producing the referral boxes.

Overheads expenses: At the project implementation office, some costs were expended as rent, Stationeries, Maintenance and Utilities. As the project also does other things, we estimated that about $10 \%$ of the cost was related to CBD's work. $10 \%$ was thus assigned to CBDs related activities.

State Programme Officer (SPO) and Monitoring and Evaluation Officer (M\&E)'s Salaries: In the four states, four SPOs and an M\&E Officer were engaged. The primary responsibility of the State programme 
Officers (SPOs) was to supervise the CBOs that engaged the CBDs. Other key tasks include work with the state ministry of health and religious and community leaders to create enabling environment for $\mathrm{FP}$ activities in the state. We assigned $50 \%$ of the SPO's time to working with CBOs working through the CBDs. Thus $50 \%$ of the SPO's time was included in this analysis. The M\&Es Officer leads in all M\&E activities covering the four states. $50 \%$ of his time was allocated to working with activities related to CBD thus $50 \%$ of his salary was used in the analysis.

Finance and admin officer's salary: The project engaged two staff for admin and finance management. Both staff are based at the head quarters. They are responsible for all finance and admin related issues of the project. We estimated that $10 \%$ of their time is spent on the work of the $\mathrm{CBO}$ and thus allocated $10 \%$ of their salary for the period to this cost.

\section{Estimating health benefits}

The analysis of health benefit encompasses only the direct health benefits that result from preventing unintended pregnancies, illnesses and deaths (among women) when women are able to delay and limit childbearing. They exclude indirect and long-term benefits and savings in health care that would accrue in both the public and the private sectors [9]. We used the following in estimating health benefits: CYP and DALY

\section{Couple Year of Protection (CYP)}

Couple Year of Protection (CYP) is the estimated protection provided by family planning (FP) services during a one-year period, based upon the volume of all contraceptives sold or distributed free of charge to clients during that period [10]. CYP is calculated by multiplying the quantity of each method distributed to clients by a conversion factor, to yield an estimate of the duration of contraceptive protection provided per unit of that method. We summed up the CYPs for each method to obtain a total CYP [11]. Periodic updated the CYP conversion factors, which are endorsed by USAID and are posted on the Agency's website [12].

\section{Disability Adjusted Life Years (DALYs)}

The Disability-Adjusted Life-Year (DALY) is a metric that combines the burden of mortality and morbidity (non-fatal health problems) into a single number. It is the primary metric used by the World Health Organization (WHO) to assess the global burden of disease to quantify the cost effectiveness of different programs $[13,14]$.

One DALY can be thought of as one lost year of "healthy" life. The sum of these DALYs across the population, or the burden of disease, can be thought of as a measurement of the gap between current health status and an ideal health situation where the entire population lives to an advanced age, free of disease and disability. DALYs for a disease or health condition are calculated as the sum of the Years of Life Lost (YLL) due to premature mortality in the population and the Years Lost due to Disability (YLD) for people living with the health condition or its consequences [13].

DALY $=$ YLL + YLD

The shortcomings of DALY as a unit of estimating health benefits are well documented [14]. We however could not lay our hands on other well-accepted unit for estimating health benefits so; we used the DALY as our unit of estimating health benefits of using community base distributors in promoting access to health commodities in this study. In this study, we used the PSI impact calculator for Nigeria [15].

\section{Cost Effectiveness Threshold}

WHO CHOICE (CHOosing Interventions that are Cost-Effective) threshold was used to determine the cost effectiveness of use of $\mathrm{CBD}$. The threshold is built on the recommendations of the Commission on Macroeconomics and Health. CHOICE uses gross domestic product (GDP) as a readily available indicator to derive the following three categories of cost effectiveness:

- Highly cost-effective (less than GDP per capita);

- Cost-effective (between one and three times GDP per capita); and

- Not cost-effective (more than three times GDP per capita [7].

Following this standard benchmarks cost effectiveness, we compared the cost incremental effectiveness ratio against thresholds defined in reference to the gross domestic product (GDP) per capita in Nigeria, which was $\$ 3,006$ as at 2013 [16].

\section{Results}

\section{Number of Community based distributing agents trained and number persons reached with BCC activities}

Available data shows that 1,510 community based distributing agents were selected, trained and participated in carrying out behaviour change communication (BCC) activities and distribution of commodities. The CBD agents were selected and trained in three waves: wave one: 480 , wave two: 410 and wave three: 530 . The community based distributors carried out behaviour change communication activities reaching a little above 30,000 in quarter one of year 2013 . This increased to a little bit above 500,000 in quarter one of year 2014 and dropped slightly to about 470,000 in quarter two of year 2014. In all the CBD agents reached 1,563,690 persons with behaviour change communication activities within the study period (Figure 1).

\section{Number of commodities distributed}

Health commodities distributed by the community based distributing agents included: Oral daily pills, Cycle beads, Male and Female Condoms and different brands of water purifiers. Records available shows that over 520,000 oral pills, 142,795 pieces of male condoms, 381,178 units of water purifiers and 10,419 tablets of Zinc were distributed by the community based distributors within the 18 months the study covered. Details in Table 1 below:

\section{Total cost of using community based distributors}

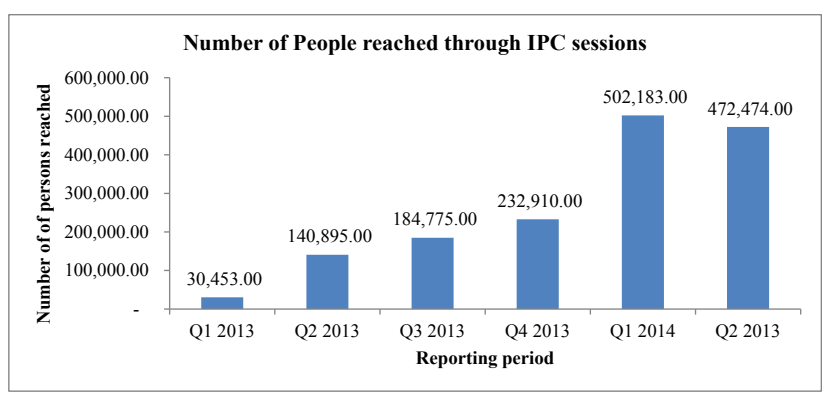

Figure 1: Number of people reached by CBDs through IPC sessions 
Citation:Ezire O, Babale IS, Usman DB, Guraguri A, Idogho O (2015) Cost Benefit Analysis of Use of Community Based Distributors in Promoting Access to Family Planning Services in Rural Communities in North Western Nigeria. J Trop Dis 3: 172. doi:10.4172/2329891X.1000172

Page 4 of 6

\begin{tabular}{|c|c|c|c|c|c|c|c|}
\hline Commodities & Q1 2013 & Q2 2013 & Q3 2013 & Q4 2013 & Q1 2014 & Q2 2013 & Total \\
\hline Daily Pill & 47,745 & 621,840 & 553,995 & 898,230 & 266,2140 & 303,1830 & 781,5780 \\
\hline Cycle beads & 678 & 2,323 & 3,552 & 1,616 & 12,972 & 4,121 & 25,262 \\
\hline Male Condoms & 238,800 & $2,261,520$ & $1,052,760$ & $2,201,760$ & $6,621,720$ & $4,758,720$ & $17,135,400$ \\
\hline Female Condom & 26,880 & 207,000 & 12,4320 & 4,8720 & 3,840 & 1,440 & 41,2200 \\
\hline Water guards & 2,654 & 3,277 & 748 & 885 & & & 7,564 \\
\hline PUR & 1,984 & 61,553 & 40,030 & 28,831 & 149,162 & 99,618 & 381,178 \\
\hline ORS & 6,419 & 5,128 & & & & & 11,547 \\
\hline Zinc & 7,369 & 3,050 & & & & & 10,419 \\
\hline
\end{tabular}

Table 1: Health Commodities distributed by IPCs January 2013 to June 2014.

\begin{tabular}{|c|c|c|}
\hline Cost Elements & Total (N) & Total (\$) \\
\hline CBO sub contract fees & $118,889,800$ & $50743,061.25$ \\
\hline M\&E Activities & $4,655,904.36$ & $29,099.40$ \\
\hline Purchase of commodities & $238,879.96$ & $1,493.00$ \\
\hline Staff capacity building & $291,139.75$ & $1,819.62$ \\
\hline Meeting with religious leaders & $4,745,359.99$ & $29,658.50$ \\
\hline Monitoring of $\mathrm{CBD}$ agent & $5,166,592.97$ & $32,291.21$ \\
\hline Monitoring of CBO Financial & $230,879.54$ & $1,443.00$ \\
\hline Production of CBD kits & $30,792,864.00$ & $192,455.40$ \\
\hline Production of MIS & $2,959,997.00$ & $18,499.98$ \\
\hline Review meetings $\mathrm{CBO}$ & $6,213,728.00$ & $38,835.80$ \\
\hline Meeting with SPO & $403,971.00$ & $2,524.82$ \\
\hline ToT for CBD agent & $3,811,530.05$ & $23,822.06$ \\
\hline Referral Boxes & $97,174.00$ & 607.34 \\
\hline Overheads Exp & 337,585 & $2,109.91$ \\
\hline SPO Salary & $5,987,582.70$ & $37,422.39$ \\
\hline Driver Salary HQ & $1,080,869.42$ & $6,755.43$ \\
\hline M\&E Officer salary & $3,221,459.71$ & $20,134.12$ \\
\hline Finance officer & $631,638.26$ & $3,947.74$ \\
\hline Finance and admin assistant & $471,687.15$ & $2,948.04$ \\
\hline Total & $190,228,643.36$ & $1,188,929.01$ \\
\hline
\end{tabular}

Table 2: Total cost by category of cost elements for 18 months.

Available records show that about $\$ 1,188,929.01$ was spent on using the community based distributors in promoting FP services with an average cost of $\$ 787.37$ for 18 months. Details cost is on Table 2 below.

\section{Total CYP and DALYs averted}

Using the USAID CYP conversion factor [11], we estimated total number of CYP generated by the community-based distributors to be about 684.124.15 CYP. Using Population Services International (PSI) DALY impact calculator [15] we estimated total DALY averted for FP commodity distribution only to be $31,077.7$ and $39,714.55$ when other health commodities distributed by the CBDs are included. Details in Table 3

Incremental Cost Effectiveness Ratio (ICER) Cost Effectiveness Analysis:

We estimated the incremental cost effectiveness ratio using the equation below:

$$
\mathrm{C} 1-\mathrm{C} 0
$$$$
\mathrm{B} 1-\mathrm{B} 0
$$

Where:

C1: Cost of using CBDs for the distribution of health commodities
C0: Cost associated with non-use of CBDs in the distribution of health commodities

B1: Health Benefit (DALY averted) with the use of CBDs

B0: Health Benefit (DALY averted) with not using CBDs

$\operatorname{ICER}=\$ 1,188,929.01-0 / 31,077.70-0 ;=\$ 38.26$

\section{Discussions}

In this study, we attempted to answer the questions: What is (are) the health benefit(s) of using CBD in promoting FP services? What is the cost of using CBD in promoting FP services? And using WHO effective threshold we attempted to answer the question, is the use of CBD a cost effective approach in promoting FP services? Within the context of this study, health benefits were measured using couple years of protection (CYP) and disability adjusted life years (DALY). We found that the use of CBD in promoting FP services contributed to over 25 million CYP and 39,714 DALYs were averted within the study period. In terms of cost of using the CBD, we found the total cost to be a little below $\$ 1.19 \mathrm{~m}$, average cost of engaging a CBD to be $\$ 787.37$ while the cost per person reached with either services or communication activities was $\$ 0.78$. Cost per CYP was less than $\$ 1$. Using the WHO CHOiCE threshold, we found the use of CBD in health commodity distribution to be very effective as the ICER (\$38.26) was less than Nigeria GDP per capita $(\$ 3,006)[16]$. While the use of CBD is not a substitute for 
Citation:Ezire O, Babale IS, Usman DB, Guraguri A, Idogho O (2015) Cost Benefit Analysis of Use of Community Based Distributors in Promoting Access to Family Planning Services in Rural Communities in North Western Nigeria. J Trop Dis 3: 172. doi:10.4172/2329891X.1000172

Page 5 of 6

\begin{tabular}{|c|c|c|c|}
\hline Commodities & Number distributed & Total CYPs & DALY Averted FP only \\
\hline Combination 3 & $7,815,792.09$ & $521,052.81$ & $17,326.70$ \\
\hline Cycle beads & $25,261.50$ & $16,841.00$ & $13,136.71$ \\
\hline Gold Circle & $17,135,440.44$ & $142,795.34$ & 599.86 \\
\hline Elegance & $412,200.00$ & $3,435.00$ & 14.43 \\
\hline Water guards & $7,564.03$ & & 139.136 .71 \\
\hline PUR & $381,178.47$ & & \\
\hline ORS & $11,547.00$ & & \\
\hline Zinc & $10,419.00$ & 68.015 .85 & \\
\hline Total & & & 242.82 \\
\hline
\end{tabular}

Table 3: CYP and DALY Averted by product and Total

clinic based FP services, the use of CBD should be promoted as it has real value for money. While poor geographical distribution of health care professionals also contributes to the dearth in manpower, the poor doctor-patient ratio of 1:6400 in Nigeria as against the World Health Organisation (WHO) standard of 1:600 remains a huge challenge, as medical schools in the country graduate between 2,500 and 4,000 new doctors annually [17]. Clearly, these health professionals cannot meet even the basic health needs of the population. To compound this problem, majority of these professionals are located in urban areas and are concerned with health services that require comparatively sophisticated training and equipment. The use of CBD can bridge the gap and bring FP services to people in rural communities in a cost effective way. For these communities, CBD is often the only means of gaining access to family planning services. Also to note that CBD services are also usually more cost-effective than clinic-based services [3] as they are community based. They are closer to the people and so more likely to reach those who need the services [18]. We found the average cost of reaching one person to be lower than what was found in a study on the actual cost of providing the intrauterine system for contraception in a UK community sexual and reproductive health setting [18]. While the settings are not necessarily comparable, it however shows that it is quite effective using CBDs in Nigeria. Our findings are also fairly consistent with the existing literature. Several quasi-experimental studies have found increasing uptake of FP services as a result of use of community based distribution agents. [19]. This result reaffirms earlier work that the use of community outreaches (which the CBD also did) can improve access to FP services [20]. Though previous work health benefits were not estimated using DALYs, this did thus an improvement over earlier work. We couldn't separate the cost of new users from those using the products continuously. Isolating these different cost and benefits may provide some understanding. Having another scenario that reflects the cost of facility-based services would have been useful but because of limited data, our study was limited to use of CBD and non-use of CBDs. The study is also limited, as the effect of annunciation was not factored in which may have some minor differences in the results. The use of CYP has its limitations, as access does not always translate to use.

\section{Conclusion}

In conclusion it is highly recommended that in resource constraint environments like Nigeria, the use of CBD be promoted, as it is a cost effective way of promoting health of people. We recommend that guidelines should be developed and their use enforced. In the dearth of health workers in most rural locations, government and development partners should commit resources to the use of CBDs. Currently, the $\mathrm{CBDs}$ receive stipends as remuneration for work done which is related to the number of people reached and the number of commodities distributed. Though this is cost effective, this should be with some caution as lessons from other studies noted that past CBD programmes that gave financial incentives for voluntary sterilisation raised concerns that they could be coercive and violate the rights of individuals and were stopped [22]. Finally it should be noted that public health interventions cannot, however, be viewed solely in terms of value for money because of the broader and longer-term impact they have on general wellbeing -not only of individuals but also the wider community. Such factors also need to be taken into account by local decision-makers [23].

\section{Acknowledgements}

We greatly appreciate the work of all authors cited in this study. We also acknowledge the project that gave us access to their financial and programmatic records.

\section{Conflict of interest}

We have no conflict of interest and no funding for this study.

\section{References}

1. National Population Commission (2009) Nigeria Demographic and Health Survey, Abuja, Nigeria.

2. National Population Commission (2013) Nigeria Demographic and Health Survey, Abuja, Nigeria.

3. WHO (1996) Institutional Repository for Information Sharing.

4. Family Health International (2006) Save the Children.

5. United Nations Population Fund (1994) Methods for Costing Family Planning Services, New York:

6. United Nations Population Fund.

7. PathFinder International (2006) Improving Reproductive Health through Community-Based Services: 25 Years of Pathfinder International Experience.

8. World Health Organization (2014) Cost effectiveness and strategic planning (WHO-CHOICE).

9. Laxminarrayan R, Chow J and Shahid-Salles SA (2014) Disease Control Priorities in Developing Countries. ( $\left.2{ }^{\text {nd }} e d n\right)$, National Center for Biotechnology Information, U.S. National Library of Medicine, USA.

10. Cohen SA (1999) The United States and the United Nations Population Fund: A Rocky Relationship. The Guttmacher Report on Public Policy 2.

11. Measure Evaluation (2014) Couple-years of protection (CYP).

12. Stover J, Bertrand JT, Shelton JD (2000) Empirically based conversion factors for calculating couple-years of protection. Eval Rev 24:3-46.

13. ***https://www.usaid.gov/

14. WHO (2014) Health statistics and information systems

15. GiveWell (2014) Interpreting the Disability-Adjusted Life-Year (DALY) metric.

16. Population Services International (2014) PSI impact Report

17. World Bank Group (2014) GDP per capita.

18. ***http://nigerianhealthjournal.com/

19. Cook L, Fleming C (2014) What is the actual cost of providing the intrauterine 
Citation:Ezire O, Babale IS, Usman DB, Guraguri A, Idogho O (2015) Cost Benefit Analysis of Use of Community Based Distributors in Promoting Access to Family Planning Services in Rural Communities in North Western Nigeria. J Trop Dis 3: 172. doi:10.4172/2329891X.1000172

Page 6 of 6

system for contraception in a UK community sexual and reproductive health setting? J Fam Plann Reprod Health Care 40: 46-53.

20. Gillespie D, Ahmed S, Tsui A, Radloff S (2007) Unwanted fertility among the poor: an inequity? Bull World Health Organ 85: 100-107.

21. White JS, Speizer IS (2007) Can family planning outreach bridge the urbanrural divide in Zambia? BMC Health Serv Res 7: 143.
22. Okech TC, Wawire NC, Mburu TK (2011) Contraceptive Use among Women of Reproductive Age in Kenya's City Slums Int J Business and Soc Sci 2.

23. Bellows NM, Askew 12, Bellows B3 (2015) Review of performance-based incentives in community-based family planning programmes. J Fam Plann Reprod Health Care 41: 146-151.

24. National Institute for Health and Care Excellence (2013) Judging whether public health interventions offer value for money. 